\title{
Aging and Panicogenic Response to Cholecystokinin Tetrapeptide: An Examination of the Cholecystokinin System
}

\author{
Alastair Flint, M.B., Jacques Bradwejn, M.D., Franco Vaccarino, Ph.D., Jolanta Gutkowska, Ph.D.,
} Roberta Palmour, Ph.D., and Diana Koszycki, Ph.D.

Older age is associated with diminished symptomatic and cardiovascular response to the panicogenic agent cholecystokinin tetrapeptide (CCK-4). We hypothesized that circulating concentrations of endogenous CCK-4 and/or CCK-8 are increased in later life, possibly due to decreased enzymatic degradation, and that this is associated with desensitization of CCK-B receptors. The study group consisted of 20 healthy subjects aged 18-30 years and 20 healthy subjects aged 65-85 years. The two groups were compared on fasting basal plasma concentrations of CCK-4, sulfated CCK-8 (CCK-8s) and nonsulfated CCK-8 (CCK-8ns), and on binding capacity of lymphocyte CCK-B receptors. Under single-blind (to subject) conditions, subjects were then administered an intravenous bolus of placebo, followed $50 \mathrm{~min}$ later by an intravenous bolus of $50 \mu \mathrm{g}$ of CCK-4. Plasma concentrations of total CCK $\left(\mathrm{CCK}_{T}\right)$ were measured 2 min before and 2, 5, 10, and 15 min after each injection. Compared with younger subjects, older subjects had a significantly higher basal plasma concentration of CCK-8s and significantly diminished binding capacity of CCK-B receptors. Following injection of placebo, plasma $C C K_{T}$ concentrations did not significantly change from baseline in either age group, but the elderly had significantly higher concentrations than the young at 2, 5, and $10 \mathrm{~min}$. Following injection of CCK-4, the plasma concentration of $\mathrm{CCK}_{T}$ was highest at 2 min and declined after that. The elderly had significantly higher $\mathrm{CCK}_{T}$ concentrations (ie. a slower decline in $C C K_{T}$ ) than the young at 5, 10, and $15 \mathrm{~min}$. These findings are consistent with our hypothesis and suggest that age-related changes in the CCK system could contribute to the diminished panicogenic response to exogenous CCK-4 in older persons.

[Neuropsychopharmacology 27:663-671, 2002]

(C) 2002 American College of Neuropsychopharmacology.

Published by Elsevier Science Inc.
From the Toronto General Hospital (AF) and Centre for Addiction and Mental Health (FV), Department of Psychiatry, University of Toronto, Toronto, Ontario, Canada; Royal Ottawa Hospital (JB, DK), Department of Psychiatry, University of Ottawa, Ottawa, Ontario, Canada; Department of Cardiovascular Biochemistry (JG), Hopital Hotel-Dieu, University of Montreal, Montreal, Quebec, Canada; and Departments of Biology, Psychiatry and Human Genetics (RP), McGill University, Montreal, Quebec, Canada.

Address correspondence to: Dr. Alastair Flint, Toronto General Hospital, 200 Elizabeth Street, 8 Eaton North - Room 238, Toronto, Ontario, M5G 2C4 Canada. Tel.: (416) 340-4788; Fax: (416) 340-4198; E-mail: alastair.flint@uhn.on.ca

Received August 17, 2001; revised March 7, 2002; accepted March 11, 2002.

Online publication: 3/12/02 at www.acnp.org/citations/ Npp031202267.
KEY WORDS: Cholecystokinin; Aging; Panic attacks; Receptor binding; Plasma concentration; Assay

Cholecystokinin (CCK) is a gastrin-like peptide with several molecular forms, ranging from 4 to 58 amino acid residues (Crawley and Corwin 1994). CCK was first isolated from the alimentary tract, where it has an important role in stimulating gallbladder contraction and the release of pancreatic enzymes. CCK is also abundant in the brain, where it functions as both a neurotransmitter and a neuromodulator. Two types of CCK receptor have been identified: CCK-A receptors, which are found in the viscera and some distinct brain regions, and CCK-B receptors, which are predomi- 
nantly located and widely distributed in the brain (Crawley and Corwin 1994).

Intravenous administration of cholecystokinin tetrapeptide (CCK-4), a selective CCK-B agonist, produces panic attacks in humans (Bradwejn 1993). The mechanism of CCK-4-induced panic is not known. However, animal and clinical work suggests that brainstem CCK-B receptors may mediate the panicogenic effects of CCK-4, possibly through direct or indirect interaction with other neurotransmitter systems (Bradwejn 1993). Prompted by epidemiologic evidence that the prevalence and incidence of panic disorder decline in later life (Flint et al. 1996), we previously investigated the effect of aging on healthy subjects' response to CCK-4. We found that older subjects had significantly fewer and less intense symptoms of panic, shorter duration of symptoms, and less autonomic reactivity to CCK-4 compared with younger subjects (Flint et al. 1998). The purpose of the current study was to determine whether there are age-related changes in the CCK system that could account for older subjects' attenuated response to CCK-4.

Studies in animals and humans have consistently found an age-related decline in sensitivity of the gallbladder and pancreas to CCK (Khalil et al. 1984, 1985a,b; Miyasaka and Kitani 1987, 1989; Masclee et al. 1988; Poston et al. 1988a, 1990; Ishizuka et al. 1993). Furthermore, animal studies have found that aging is associated with a reduction in the mRNA level of pancreatic CCK-A receptors (Miyasaka et al. 1995a) and a decreased density of CCK receptors in the pancreas and gallbladder (Poston et al. 1988a,b). Very little is known about the effect of aging on brain CCK, and to our knowledge there are no age-related data pertaining to brainstem CCK-B receptors. Harro and Oreland (1992) found a significant reduction in the number of CCK-B receptors in the hippocampus, but not the frontal cortex, of old compared with young rats. Ceruletide, a CCK-8 analog, improved auditory event-related potential indicators of cognitive processing in younger but not older humans (Dodt et al. 1996), raising the possibility of diminished sensitivity of brain CCK receptors in the elderly. On the basis of these findings, we postulated that aging may be associated with diminished sensitivity of CCK-B receptors, thereby lessening the potential for CCK-4-induced panic in later life.

Aging has also been associated with changes in the extracellular concentration of CCK. Two studies, which measured CCK fragments 12 amino acid residues or longer, found that fasting plasma concentrations of CCK were higher in older than younger healthy subjects (Khalil et al. 1985a; MacIntosh et al. 1999). One possible explanation for this finding is that release of CCK is increased in later life. However, studies in animals have found an age-related reduction in the synthesis and release of CCK from the cells of the brain and small intestine (Ohta et al. 1995; Miyasaka et al. 1995b, 1997). Another possibility is that decreased turnover could result in extracellular accumulation of CCK. Although we are not aware of any data that pertain to the effect of aging on peptidases that degrade CCK, animal work has found an age-related decrease in the activity of some other types of proteolytic enzymes (Agarwal and Sohal 1994; Cao and Cutler 1995). In theory, a reduction in aminopeptidase activity could result in sustained higher extracellular concentrations of CCK and a consequent decrease in CCK receptor sensitivity in the elderly.

Because of the difficulty in directly examining central neurotransmitter activity in humans, studies have traditionally relied on peripheral measures that may mirror brain function. A sensitive and specific assay system was recently developed to measure plasma concentrations of the CCK-B receptor agonists CCK-4, sulfated CCK-8 (CCK-8s), and nonsulfated CCK-8 (CCK-8ns) (Merani et al. 1997). This assay allowed us to explore the theory that extracellular concentrations of CCK-4 and/or CCK-8 are increased in later life, possibly due to decreased enzymatic degradation, and that this is associated with down-regulation of CCK-B receptors. We hypothesized that, compared with healthy younger subjects, healthy older subjects would have:

1. Higher basal plasma concentrations of endogenous CCK-4 and/or CCK-8 (reflecting a higher extracellular concentration of these forms of CCK)

2. Slower decline of plasma CCK concentrations following intravenous administration of CCK-4 (reflecting decreased degradation of CCK)

3. Diminished binding capacity of lymphocyte CCK-B receptors (used as a proxy for brain CCK-B receptors).

\section{METHODS}

\section{Subjects}

At the time that this study was designed, we did not have the requisite data to perform a power analysis to estimate the sample size. Therefore, the size of the study group was based on our previous work in which 20 young and 20 old subjects were sufficient to demonstrate robust between-group differences in symptomatic and cardiovascular responses to injected CCK-4 (Flint et al. 1998). The study group consisted of 10 men and 10 women aged 18-30 years (mean age $=24.5$ years, $\mathrm{SD}=3.6$ ) and 10 men and 10 women aged 65-85 years (mean age $=73.4$ years, $\mathrm{SD}=5.0$ ). All were healthy volunteers recruited through advertisement. On the basis of a structured psychiatric interview (SCID-NP) (Spitzer et al. 1995), they fulfilled DSM-IV criteria for normal subjects with no current or past psy- 
chiatric disorder or history of panic attacks. None of the subjects met DSM-IV criteria for dementia. Subjects were physically healthy as determined by history, physical examination, and normal complete blood count, renal function tests, liver function tests, serum calcium, serum glucose, and thyroid function tests. Subjects were excluded from the study if they met any of the following criteria: (1) a history of depression, panic disorder, or agoraphobia in any first-degree relative; (2) a history of neurological, cardiac, or gastrointestinal disorder; (3) use of benzodiazepine, antidepressant, antipsychotic, anticonvulsant, barbiturate, $\beta$-blocking, ACE inhibiting, calcium channel blocking, or steroid medications within three months of entry into the study; (4) use of cocaine, amphetamines, hallucinogens, opioids, or cannabis within 12 months of entry into the study and/or a positive test for any of these substances or benzodiazepines on a urine toxicology screen at the time of evaluation; (5) current participation in other research studies. Premenopausal women who were not using a reliable method of contraception were also excluded from the study, and all premenopausal women who participated in the study had a negative pregnancy test at the time of evaluation. Women were studied irrespective of the phase of their menstrual cycle. With the exception of serum albumin (which was normal), indices of nutritional status were not specifically measured, but by history and physical examination all subjects were adequately nourished.

All subjects gave written informed consent after the details of the study had been fully explained to them. Younger and older subjects were given exactly the same explanation about the study procedure and the possible psychological and physical effects of intravenously administered CCK-4 and placebo. The study was approved by the Research Ethics Board of the Toronto General Hospital and was carried out in accordance with the Declaration of Helsinki.

\section{Study Design}

The study used a single-blind (to the subject), placebocontrolled, fixed-order design. Each subject received an intravenous bolus injection of placebo and, $50 \mathrm{~min}$ later, an intravenous bolus injection of CCK-4. CCK-4 was administered second so as not to confound endogenous plasma CCK concentrations during the placebo phase of the study. Laboratory analyses were performed blind to the identity of the subjects and the phase (i.e. placebo versus CCK-4 injection) of the study.

\section{Symptomatic Measures}

Symptoms of panic were rated using the Panic Symptom Scale (PSS) (Bradwejn et al. 1990) which lists 18 symptoms classically experienced during panic attacks.
This scale has been validated in previous studies (Bradwejn 1993). Ratings on individual items range from 0 (not present) to 4 (very severe). The following measures were obtained from the PSS: a score of the total number of symptoms (number of items scored 1 or higher) and a sum intensity score (sum of intensity ratings).

\section{Procedure}

The experiment took place between 8:00 and 10:00 A.M. in the Clinical Investigation Unit of the Toronto General Hospital. Subjects had fasted for $12 \mathrm{~h}$ prior to the study. Subjects were seated in a reclining chair in a quiet, moderately lighted room. An intravenous catheter was inserted into an antecubital vein and a physiological saline drip was started. A blood pressure cuff with a pulse monitor attached to a Dinamap monitor was applied to the other arm. Thirty minutes prior to the placebo challenge, blood samples were drawn through a 3-way stopcock in the intravenous line for determination of lymphocyte binding of CCK and basal plasma concentrations of CCK-4, CCK-8s and CCK-8ns. At this stage and subsequent stages of the study, blood samples for the plasma concentration of CCK were collected in chilled syringes containing the enzyme inhibitors aprotinin $(1000 \mathrm{IU} / \mathrm{ml})$, bestatin $(0.03 \mathrm{mM})$, and phenylmethylsulphonyl fluoride (PMSF) $\left(10^{-5} \mathrm{~mol} / \mathrm{L}\right)$. The samples were immediately dispensed into chilled EDTA tubes on ice and centrifuged at $3000 \mathrm{rpm}$ at $4^{\circ} \mathrm{C}$ for $15 \mathrm{~min}$. Plasma was stored at $-70^{\circ} \mathrm{C}$ until use. Two minutes prior to the placebo challenge, another blood sample was obtained through the stopcock to measure the plasma concentration of total CCK $\left(\mathrm{CCK}_{\mathrm{T}}\right)$, which was the combined concentrations of CCK-4, CCK-8s, and CCK-8ns. At this stage, blood pressure and heart rate (vital signs) were recorded.

Subjects were then administered an intravenous bolus (less than $5 \mathrm{~s}$ ) injection of $2.5 \mathrm{ml}$ of normal saline. They were asked to describe symptoms experienced following the injection and report when the effect of the injection had abated. The symptoms associated with the injection, as well as their onset and duration, were recorded by the study psychiatrist. Once the effect of the injection had abated, subjects were asked to rate the intensity of each symptom on the PSS. The onset of symptoms was defined as the time from the injection to the first symptom and the duration was defined as the time from the onset of symptoms until the time the symptoms abated. If the subject did not experience symptoms, he or she was observed for $5 \mathrm{~min}$ from the time of injection before the PSS was completed. Vital signs were obtained at $30 \mathrm{~s}$ intervals following the injection for a 5 -min period and then at $1 \mathrm{~min}$ intervals for the next $10 \mathrm{~min}$. Blood samples to measure the plasma concentration of $\mathrm{CCK}_{\mathrm{T}}$ were obtained through the stopcock at 2, 5, 10, and $15 \mathrm{~min}$ after the injection. CCK is subject 
to rapid proteolytic cleavage and the timing of blood samples was designed to detect the rapid elevation and decline in plasma CCK concentrations that was anticipated following intravenous injection of CCK-4. After monitoring of symptoms and vital signs and the collection of blood samples was completed, subjects rested for $30 \mathrm{~min}$ with the intravenous catheter still in place. Subjects then underwent challenge with CCK-4. Two minutes prior to this challenge, vital signs were recorded and a blood sample to measure the plasma $\mathrm{CCK}_{\mathrm{T}}$ concentration was obtained through the stopcock. Subjects were then administered an intravenous bolus of $50 \mu \mathrm{g}(2.5 \mathrm{ml})$ of CCK-4 and exactly the same procedure as for the placebo phase of the study was followed.

\section{Lymphocyte Binding Assay}

Preparation of Lymphocytes. Lymphocytes were isolated from whole blood using LeucoPrep tubes (BectonDickenson), then placed in culture (RPMI 1640, containing phytohemaglutinin, interleukin-2, and catalase) for a period of one to three weeks to achieve an eightfold expansion of cell number (Adolph et al. 1988). Prior to binding assays, cells were harvested, washed once in phosphate buffered saline containing $25 \mathrm{mM}$ HEPES and preincubated for $15 \mathrm{~min}$ at $25^{\circ} \mathrm{C}$ with inhibitors of proteolysis (bestatin, aprotinin, PMSF) in $50 \mathrm{mM}$ Tris$\mathrm{Cl}, \mathrm{pH} 7.4$, containing $0.1 \mathrm{mg} / \mathrm{ml}$ bovine serum albu$\mathrm{min}$ and $10 \mathrm{mM}$ magnesium chloride.

Binding Assays. Aliquots containing $2 \times 105$ lymphocytes, prepared as described above, were incubated in the presence of graded concentrations of ${ }^{125} \mathrm{I}-\mathrm{CCK}-8 \mathrm{~ns}$, to yield final concentrations of between 0.5 and $50 \mathrm{nM}$ CCK-8. Non-specific binding was defined with unlabeled CCK-4, at a concentration of $1 \mu \mathrm{M}$. All ligands were diluted with assay buffer containing inhibitors of proteolysis. Reaction tubes were incubated for $45 \mathrm{~min}$ at $25^{\circ} \mathrm{C}$, then rapidly centrifuged at $20,000 \mathrm{rpm}$ for $10 \mathrm{~min}$. The supernatant was decanted and the pellet washed rapidly with two successive aliquots of $0.5 \mathrm{ml}$ assay buffer. Pellets were counted in a $\gamma$ counter (LKB-Wallac). Protein was determined by the method of Lowry et al. (1951). Specific binding was computed and maximal binding capacity estimated according to the method of Munson and Rodbard (1980), as implemented in the computer program LIGAND (BioSoft, MacIntosh version).

\section{Cholecystokinin Assay}

The plasma concentration of cholecystokinin was determined by the method described by Merani et al. (1997). Plasma was extracted using Sep-Pak $\mathrm{C}_{18}$ cartridges (Waters). Each plasma extract was directly assayed for the concentration of $\mathrm{CCK}_{\mathrm{T}}$. In addition, the basal (-30 min) samples were applied to high performance liquid chromatography (HPLC) to measure individual plasma concentrations of CCK-4, CCK-8s, and CCK-8ns.

HPLC Fractionation. Reverse phase HPLC on a $\mathrm{C}_{18}$ $\mu$ Bondapak Column (Waters) using a $20-50 \%$ gradient of acetonitrile (ACN) and $\mathrm{dH}_{2} \mathrm{O}$, each containing $0.1 \%$ trifluoroacetic acid, was used to separate standard preparations of CCK-4, CCK-8s, and CCK-8ns with a flow rate of $1 \mathrm{ml} /$ minute. Forty fractions of $1 \mathrm{ml}$ each were collected and placed in a speed-vac overnight. Lyophilized plasma samples were reconstituted in $20 \%$ ACN and applied to HPLC in a similar manner.

Radioimmunoassay. The immunoassay uses an antibody raised against CCK-4 coupled to thyroglobulin and ${ }^{125} \mathrm{I}$ Bolton-Hunter CCK-4 as tracer. The antibody detects CCK-4, CCK-8s, and CCK-8ns with equal affinity. The range of the standard curve was determined to be $0.4-400 \mathrm{pg} \mathrm{CCK} / \mathrm{ml}$ of plasma $(0.7-672 \mathrm{fmol} \mathrm{CCK}-4$ equivalents $/ \mathrm{ml}$ of plasma). Intra-assay and inter-assay coefficients of variation were $8 \%$ and $9 \%$, respectively. Specific activity of the monoiodinated tracer was 1025 $\mathrm{Ci} / \mathrm{mmol}$. Binding of tracer in the absence of standard (zero binding) was $15.3 \% \pm 0.2 \%$ at a $1: 10,000$ antisera dilution, with half-maximal displacement (ED50) at $38.5 \pm 1.4 \mathrm{fmol}$. Nonspecific binding was calculated as $1.4 \% \pm 0.1 \%$.

\section{Statistical Analyses}

The normality of data distribution was tested with the Shairo-Wilk statistic test. Continuous data that were not normally distributed were subject to logarithmic transformation when the minimum value was above zero or square root transformation when the minimum value included zero. Means, standard deviations, and standard errors are, however, reported in their original units. Plasma $\mathrm{CCK}_{\mathrm{T}}$ levels below the lower limit of quantification (LOQ) were assigned a value of $0.1 \mathrm{pg} /$ $\mathrm{ml}$ for mean calculation; that is, the maximal plasma level below the LOQ.

Independent $t$-tests were used to compare young and old groups on basal concentrations of CCK-4, CCK$8 \mathrm{~s}, \mathrm{CCK}-8 \mathrm{~ns}$, and lymphocyte binding. One-way repeated-measures analysis of variance (ANOVA) was used to analyze plasma $\mathrm{CCK}_{\mathrm{T}}$ concentrations, PSS measurements, and maximum change from baseline in blood pressure and heart rate. Age of subjects was the between-group variable, and injection (CCK or placebo) and time of assessment were within-subject variables. Statistically significant main effects were analyzed by tests of simple effects. Spearman's correlation was used to examine the linear association between lymphocyte binding of CCK and: (1) basal plasma CCK concentrations; (2) symptomatic measures of panic following 
CCK-4 injection. For all analyses, statistical significance was set at $p \leqslant .05$ (2-tailed test).

\section{RESULTS}

\section{Subject Characteristics}

At initial evaluation, subjects completed the Hospital Anxiety and Depression Scale (HADS) (Zigmond and Snaith 1983) and the Anxiety Sensitivity Index (ASI) (Peterson and Reiss 1992), and their cognitive function was quantified by the Minimental State (Folstein et al. 1975). Young and old groups, respectively, had mean (SD) scores of 0.9 (1.0) and 1.5 (1.5) on the depression subscale of the HADS, 2.5 (2.2) and 2.5 (1.6) on the anxiety subscale of the HADS (HADS-A), 6.7 (6.3) and 9.8 (5.7) on the ASI, and 29.8 (0.7) and 29.3 (1.1) on the Minimental State. There were no statistically significant differences between groups on any of these measures. Mean scores on all of these measures were well within the range for normal subjects.

\section{Symptomatic and Cardiovascular Comparisons Between Young and Old Subjects}

Following injection of placebo, there was no difference between young and old groups on PSS scores, or maximal change in systolic or diastolic blood pressure from baseline. However, maximal change in heart rate was lower in the older group $\left(\mathrm{F}_{1,38}=4.72, p=.04\right)$. In response to CCK-4 injection, older subjects had fewer symptoms $\left(\mathrm{F}_{1,38}=15.29, p<.001\right)$, less intense symptoms $\left(\mathrm{F}_{1,38}=19.65, p<.001\right)$, shorter duration of symptoms $\left(\mathrm{F}_{1,38}=6.53, p<.02\right)$, and less change in heart rate $\left(\mathrm{F}_{1,38}=11.55, p=.002\right)$ compared with younger subjects. There was no significant Gender effect or Gender $X$ Group interaction for any of these analyses.

\section{Basal CCK Measures}

Fractionated CCK data were not available for three younger subjects and two older subjects; in three cases (2 old, 1 young) no peaks were detected on HPLC, and in one case (young) six peaks rather than three peaks appeared and the data could not be interpreted, and technical problems interfered with HPLC in the remaining case (young). Lymphocyte binding data were not available for three younger subjects and one older subject; in those cases, lymphocytes did not grow to a level that would allow replicate aliquots.

CCK-B receptor binding was $41.8(7.1) \mathrm{fmol} / \mathrm{mg}$ in older subjects and $51.9(9.0) \mathrm{fmol} / \mathrm{mg}$ in younger subjects $(\mathrm{t}=3.77, \mathrm{df}=34, p=.001)$. With respect to basal plasma concentrations of CCK, CCK-8s was the most abundant form, accounting for $81.3 \%$ of the mean total concentration of CCK in young subjects and $90.6 \%$ of
Table 1. Basal Fasting Plasma Concentrations of CCK-4, CCK-8s, and CCK-8ns in Young and Old Healthy Subjects.

\begin{tabular}{lcccc}
\hline & $\begin{array}{c}\text { Young } \\
(\mathbf{n = 1 7 )}\end{array}$ & $\begin{array}{c}\text { Old } \\
(\mathbf{n = 1 8 )}\end{array}$ & $\begin{array}{c}\mathbf{t} \\
\mathbf{( d f = 3 3 )}\end{array}$ & $\boldsymbol{p}$ \\
\hline CCK-4 $(\mathrm{pg} / \mathrm{ml})$ & $0.8(1.4)$ & $1.5(2.7)$ & -0.65 & .522 \\
CCK-8s $(\mathrm{pg} / \mathrm{ml})$ & $6.4(8.0)$ & $29.4(60.1)$ & -2.08 & .046 \\
CCK-8ns $(\mathrm{pg} / \mathrm{ml})$ & $0.7(1.2)$ & $1.5(3.3)$ & -0.93 & .360 \\
\hline
\end{tabular}

Values are expressed as mean (SD)

the total in older subjects. CCK-4 and CCK-8ns, respectively, accounted for an average of $10.3 \%$ and $8.4 \%$ of the total in young subjects and $4.7 \%$ and $4.7 \%$ of the total in older subjects. Older subjects had a significantly higher basal plasma concentration of CCK-8s than younger subjects $(\mathrm{t}=-2.08, \mathrm{df}=33, p=.046)$ (Table 1$)$. There were no statistically significant differences between the two groups on basal plasma concentrations of CCK-4 or CCK-8ns (Table 1).

\section{Plasma $\mathrm{CCK}_{\mathrm{T}}$ Concentrations following Placebo and CCK-4 Injections}

We initially performed ANOVA to include both placebo and CCK-4 phases of the study, using plasma $\mathrm{CCK}_{\mathrm{T}}$ concentrations $2 \mathrm{~min}$ before the administration of placebo as the baseline. There were significant main effects of Time $\left(\mathrm{F}_{4,152}=147.83, p<.001\right)$, Injection $\left(\mathrm{F}_{1,38}=\right.$ $368.45, p<.001)$ and Group $\left(\mathrm{F}_{1,38}=7.94, p=.01\right)$, and significant interactions of Time $\mathrm{X}$ Injection $\left(\mathrm{F}_{4,152}=\right.$ $133.82, p<.001)$, Time $X$ Group $\left(\mathrm{F}_{4,152}=4.35, p=.002\right)$, and Time $X$ Injection $X$ Group $\left(\mathrm{F}_{4,152}=4.57, p=.002\right)$. There was no significant main effect of Gender or Gender X Group interaction.

Since there was a significant main effect for Injection and significant interactions for Injection, we proceeded to separately analyze placebo and CCK-4 phases of the study. $\mathrm{CCK}_{\mathrm{T}}$ concentrations $2 \mathrm{~min}$ prior to placebo injection and 2 min prior to CCK-4 injection were, respectively, the baseline measure for each of these analyses. Following placebo injection, there was no significant effect of Time, but there was a significant effect of Group $\left(\mathrm{F}_{1,38}=5.74, p=.02\right)$ and a significant Time $X$ Group interaction $\left(\mathrm{F}_{4,152}=2.73, p=.04\right)$. Tests of simple effects found that older subjects had significantly higher $\mathrm{CCK}_{\mathrm{T}}$ concentrations at $2 \mathrm{~min}\left(\mathrm{~F}_{1,38}=9.5, p=.004\right), 5 \mathrm{~min}\left(\mathrm{~F}_{1,38}=\right.$ $5.67, p=.02)$, and $10 \mathrm{~min}\left(\mathrm{~F}_{1,38}=4.85, p=.03\right)$, and the higher concentration at $15 \mathrm{~min}$ approached statistical significance $\left(\mathrm{F}_{1,38}=3.89, p=.056\right)$ (Figure 1 ).

Following CCK-4 injection, there was a significant effect of Time $\left(\mathrm{F}_{4,152}=195.33, p<.001\right)$ and Group $\left(\mathrm{F}_{1,38}=\right.$ $8.19, p=.007)$, and a significant Time $X$ Group interaction $\left(\mathrm{F}_{4,152}=5.17, p=.001\right)$. In both groups, $\mathrm{CCK}_{\mathrm{T}}$ concentrations were highest at the 2 min point following CCK-4 injection and declined after that (Figure 2). 


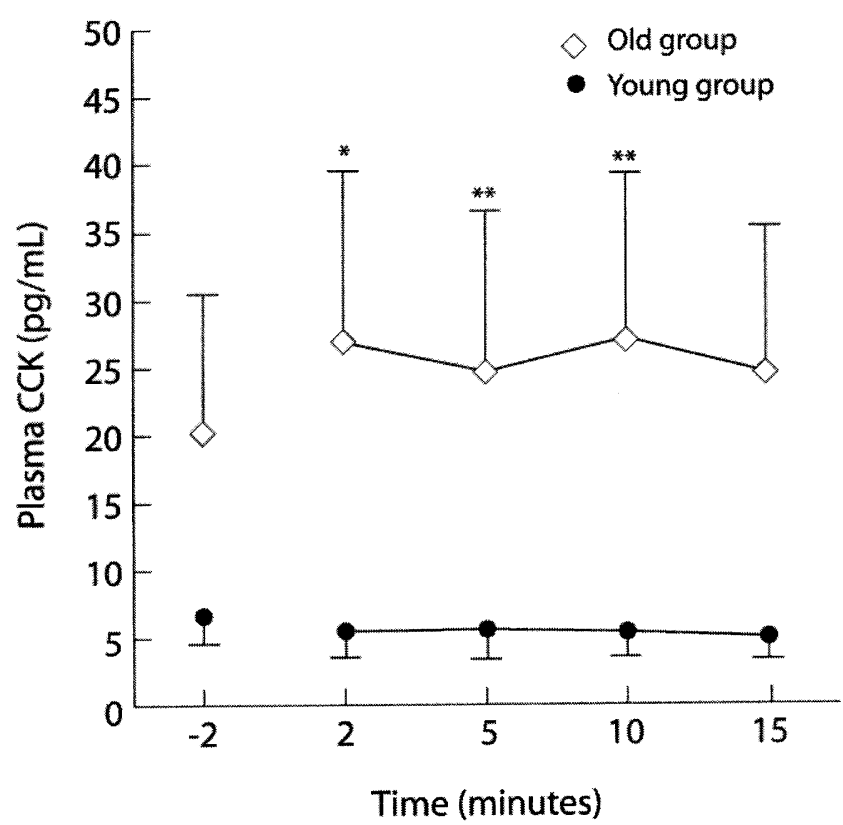

Figure 1. Plasma $\mathrm{CCK}_{\mathrm{T}}$ concentrations in young and old healthy volunteers at $2 \mathrm{~min}$ before and 2, 5, 10, and $15 \mathrm{~min}$ after placebo injection. Values are mean \pm SEM. Between group comparisons: ${ }^{*} p<.01,{ }^{* *} p<.05$.

$\mathrm{CCK}_{\mathrm{T}}$ concentrations at the final 15 min sampling point remained significantly above baseline in both younger and older groups $\left(\mathrm{F}_{1,19}=7.34, p=.014\right.$ and $\mathrm{F}_{1,19}=46.27$, $p<.001$, respectively). Between-group comparisons found that older subjects had higher $\mathrm{CCK}_{\mathrm{T}}$ concentrations (that is, a slower decline in $\mathrm{CCK}_{\mathrm{T}}$ ) than younger subjects at $5 \mathrm{~min}\left(\mathrm{~F}_{1,38}=6.38, p=.016\right), 10 \mathrm{~min}\left(\mathrm{~F}_{1,38}=\right.$ $16.55, p<.001)$, and $15 \min \left(\mathrm{F}_{1,38}=23.89, p<.001\right)$.

\section{Measures of Association}

There were no statistically significant correlations between lymphocyte binding of CCK and basal plasma concentrations of CCK-4, CCK-8s, or CCK-8ns. Based on the 32 subjects for whom these data were available, Spearman correlation coefficients were -0.122 for CCK-4, -0.229 for CCK-8s, and 0.019 for CCK-8ns. There were, however, statistically significant correlations between CCK binding and sum intensity of symptoms $(\mathrm{n}=36 ; \mathrm{r}=0.354, p=.034)$ and duration of symptoms $(\mathrm{n}=36 ; \mathrm{r}=0.357, p=.033$ ) following CCK-4 injection; the correlation coefficient for number of panic symptoms was $0.267(p=.12)$. When tested in stepwise multiple linear regression models that included HAD-A and ASI scores, lymphocyte binding remained significantly associated with duration of symptoms (standardized $\beta=0.40, \mathrm{t}=2.54, p=.016$ ) and approached statistical significance in its association with sum intensity of symptoms (standardized $\beta=$ $0.32, \mathrm{t}=1.95, p=.059)$. HAD-A and ASI scores were

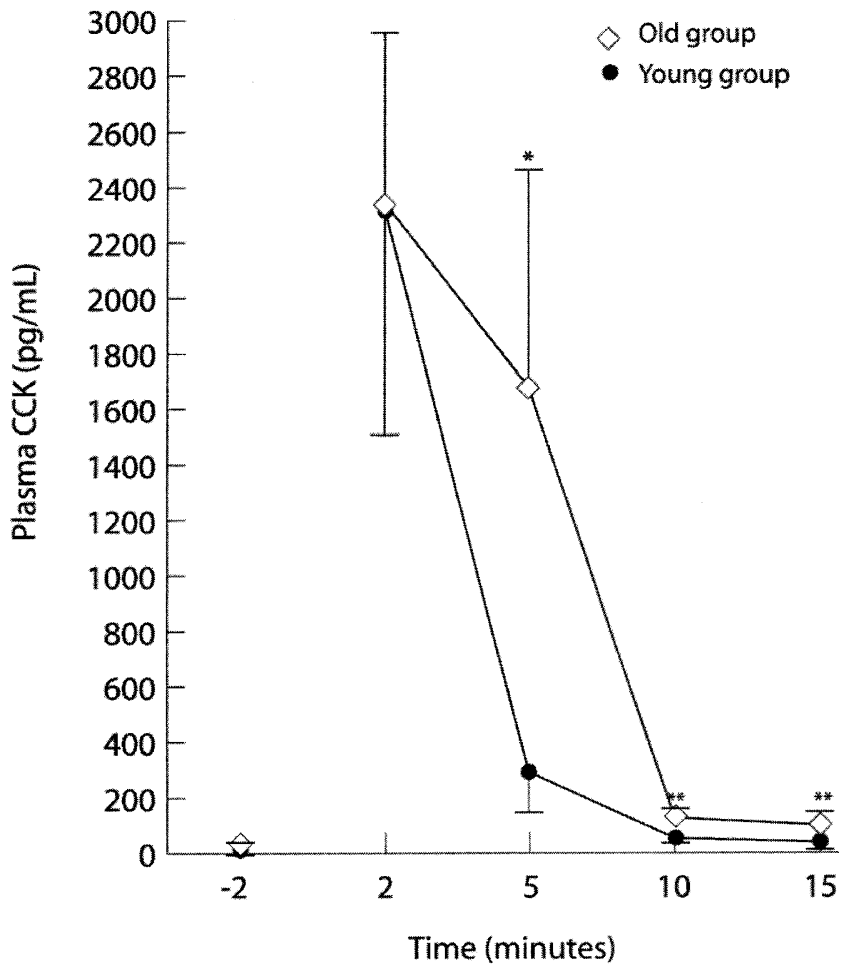

Figure 2. Plasma $\mathrm{CCK}_{\mathrm{T}}$ concentrations in young and old healthy volunteers at $2 \mathrm{~min}$ before and at 2, 5, 10, and $15 \mathrm{~min}$ after CCK-4 injection. Values are mean \pm SEM. Between group comparisons: ${ }^{*} p<.02,{ }^{* *} p<.001$.

not statistically significant variables in either of these models.

\section{DISCUSSION}

The main findings of this study were that, compared with healthy younger subjects, healthy older subjects had a diminished binding capacity of lymphocyte CCK-B receptors, a higher basal plasma concentration of CCK-8s, higher plasma concentrations of $\mathrm{CCK}_{\mathrm{T}}$ during the placebo phase of the study, and a slower decline in the plasma concentration of $\mathrm{CCK}_{\mathrm{T}}$ following injection of CCK-4. Moreover, in keeping with our previous work (Flint et al. 1998), older subjects had significantly less symptomatic response and less increase in heart rate than younger subjects when injected with CCK-4.

The goal of this study was to determine whether there are age-related changes in the CCK system that could account for the attenuated panicogenic response to CCK-4 among older people. Preclinical and clinical data suggest that exogenous CCK-4 exerts its panicogenic effect via the central nervous system (Bradwejn 1993). If this is the case, an obvious limitation of our study is that it examined peripheral, rather than central, 
measures of CCK. At the current time, however, it is not possible to measure CCK-B receptor binding, synaptic concentrations of CCK, or CCK kinetics in the living human brain. Thus, we must rely on peripheral measures to make inferences about brain CCK function. Nevertheless, CCK activity of lymphocytes is thought to mirror that of central neurons (Brambilla et al. 1993) and there is some evidence for a relation between CCK levels in plasma and brain (Fink et al. 1998). Thus, while we recognize the need for caution in extrapolating our findings to brain function, they do provide indirect support for the hypothesis that age-related changes in brain CCK may contribute to the diminished panicogenic response to CCK-4 in later life.

To our knowledge, this is the first study to have examined the effect of aging on CCK-B receptor binding in humans. Our finding corresponds with data showing an age-related reduction in the concentration of CCK receptors in the alimentary tract and certain brain regions of animals (Poston et al. 1988a,b; Harro and Oreland 1992). Although we found that receptor binding capacity was diminished in older subjects, we do not know the cause. We postulated that elevated endogenous concentrations of CCK- 4 and/or CCK- 8 could result in down-regulation of CCK-B receptors. If such a mechanism exists, it may be more complicated than a simple linear association, since we did not find meaningful correlations between plasma concentrations of these CCK fragments and CCK-B receptor binding. On the other hand, we did find statistically significant, albeit modest, correlations between CCK-B receptor binding and the sum intensity and duration of panic symptoms following CCK-4 injection. In other words, subjects with a lower concentration of receptor binding had a tendency toward less intense and briefer symptoms of panic than those with a higher concentration of binding. This is compatible with the hypothesis that the age-related attenuated response to CCK-4 may be related to diminished CCK-B receptor function.

Consistent with recent work by MacIntosh et al. (2001), we found that the mean fasting plasma concentration of combined CCK- 8 was more than four times higher in older than younger subjects. Although we did not find statistically significant differences between the two groups in basal concentrations of CCK-4 or CCK-8ns, it is worth noting that the mean concentration of each of these fragments was approximately twice as high in older than younger subjects. Inadequate sample size and a type II error may have contributed to these negative statistical results. As it turns out, based on the 35 subjects for whom these data were available, there was only a $17 \%$ probability of detecting a statistically significant difference between groups for either CCK-4 or CCK-8ns. We actually needed 160 subjects per group for there to have been an $80 \%$ probability of detecting an actual significant difference between groups in these two fragments.

The third component of this experiment was to examine the effect of aging on the kinetics of degradation of CCK. Following administration of placebo, the plasma concentration of $\mathrm{CCK}_{\mathrm{T}}$ did not significantly change from baseline in either age group. However, in keeping with our findings regarding the basal concentration of CCK-8, the mean plasma concentration of $\mathrm{CCK}_{\mathrm{T}}$ was four to five times higher in older than younger subjects at each of the four time points during the placebo phase of the study. Following bolus injection of CCK-4, there was a rapid rise in the concentration of $\mathrm{CCK}_{\mathrm{T}}$, which was highest at the 2 min mark and declined at subsequent points of measurement. This kinetic profile was the same as that described by Dépot et al. (1998) in young healthy men. Based on the substantial increase in plasma $\mathrm{CCK}_{\mathrm{T}}$ concentration after injection of CCK-4, we can assume that the plasma level measured after this injection was predominantly tetrapeptide fragment. Previous research has shown that CCK-4 in plasma undergoes proteolysis by aminopeptidases (Koulischer et al. 1982). It is of interest, therefore, that the decline in plasma $\mathrm{CCK}_{\mathrm{T}}$ following CCK-4 injection was slower in older than younger subjects. Indeed, even when the decline in CCK had leveled off at $10 \mathrm{~min}$ and $15 \mathrm{~min}$ after the injection (but, nevertheless, CCK remained significantly above baseline values) plasma concentrations of $\mathrm{CCK}_{\mathrm{T}}$ were significantly higher in the older group. This result would suggest that proteolytic degradation of the exogenous CCK-4 was reduced in the elderly. We need to emphasize, however, that although these kinetic data are consistent with our hypothesis of an agerelated reduction in enzymatic degradation of CCK, the hypothesis is speculative and unproven. An extensive search of the literature did not find any data that pertain to the effect of aging on aminopeptidase degradation of CCK- 4 or CCK-8. This area warrants further investigation.

Finally, one needs to be cognizant of the fact that our findings pertain to a model of panic in healthy volunteers. It remains to be determined whether age-related changes in the CCK system (or, for that matter, other neurotransmitter systems) are of relevance to the diminished prevalence and incidence of actual panic disorder in later life.

\section{ACKNOWLEDGMENTS}

The authors thank Ivana Furimsky, Aleks Dabic, Nickie Pinellis, Celine Coderre, and Paul Miceli for their assistance with this research. This study was supported by grant \#7176013 from the Queen Elizabeth Hospital Research Institute, Toronto. 


\section{REFERENCES}

Adolph K, Kucey MT, Hodges SD, Carter RJ, Snyder FF (1988): Interleukin-2-dependent T lymphocytes for the diagnosis and investigation of inherited metabolic disorders. Clin Chim Acta 173:147-155

Agarwal S, Sohal RS (1994): Aging and proteolysis of oxidised proteins. Arch Biochem Biophys 309:24-28

Bradwejn J (1993): Neurobiological investigations into the role of cholecystokinin in panic disorder. J Psychiatr Neurosci 18:178-188

Bradwejn J, Koszycki D, Meterissian G (1990): Cholecystokinin-tetrapeptide induces panic attacks in patients with panic disorder. Can J Psychiatry 35:83-85

Brambilla F, Bellodi L, Perna G, Garberi A, Panerai A, Sacerdote P (1993): Lymphocyte cholecystokinin concentrations in panic disorder. Am J Psychiatry 150:1111-1113

Cao G, Cutler RG (1995): Protein oxidation and aging. II. Difficulties in measuring alkaline protease activity in tissues using the fluorescamine procedure. Arch Biochem Biophys 320:195-201

Crawley JN, Corwin RL (1994): Biological actions of cholecystokinin. Peptides 15:731-755

Dépot M, Merani S, Bradwejn J, Mukherjee J, Caillé J, Gutkowska J, Caillé G (1998): Effect of oral ondansetron on total cholecystokinin plasma levels following CCK-4 panic challenge procedure in healthy men. J Psychiatry Neurosci 23:298-304

Dodt C, Sarnighausen H-E, Pietrowsky R, Fehm HL, Born J (1996): Ceruletide improves event-related potential indicators of cognitive processing in young but not in elderly humans. J Clin Psychopharmacol 16:440-445

Fink H, Rex A, Voits M (1998): Major biological actions of CCK - a critical evaluation of research findings. Exp Brain Res 123:77-83

Flint AJ, Cook JM, Rabins PV (1996): Why is panic disorder less frequent in late-life? Am J Geriatr Psychiatry 4:96109

Flint AJ, Koszycki D, Vaccarino FJ, Cadieux A, Boulenger JP, Bradwejn J (1998): Effect of aging on cholecystokinininduced panic. Am J Psychiatry 155:283-285

Folstein MF, Folstein SE, McHugh PR (1975): “Mini-Mental State": a practical method for grading the cognitive state of patients for the clinician. J Psychiatr Res 12:189198

Harro J, Oreland L (1992): Age-related differences of cholecystokinin receptor binding in the rat brain. Prog Neuropsychopharmacol Biol Psychiat 16:369-375

Ishizuka J, Murakami M, Nichols GA, Cooper CW, Greeley GH Jr, Thompson JC (1993): Age-related changes in gallbladder contractility and cytoplasmic $\mathrm{Ca} 2+$ concentration in the guinea pig. Am J Physiol 264:G624-629

Khalil T, Mate L, Greeley GH, Thompson JC (1984): Decreased gallbladder responsiveness to CCK-8 in aged rabbits. Gastroenterology 86:1134A

Khalil T, Walker JP, Wiener I, Fagan CJ, Townsend CM, Greeley GH, Thompson JC (1985a): Effect of aging on gallbladder contraction and release of cholecystokinin33 in humans. Surgery 98:423-429
Khalil T, Fujimura M, Townsend CM, Greeley GH, Thompson JC (1985b): Effect of aging on pancreatic secretion in rats. Am J Surg 149:120-125

Koulischer D, Moroder L, Deschodt-Lanckman M (1982): Degradation of cholecystokinin octapeptide, related fragments and analogs by human and rat plasma in vitro. Regul Pept 4:127-139

Lowry OH, Rosebrough NJ, Farr AL, Randall RJ (1951): Protein measurement with the Folin phenol reagent. J Biol Chem 193:265-275

MacIntosh CG, Andrews JM, Jones KL, Wishart JM, Morris HA, Jansen JBMJ, Morley JE, Horowitz M, Chapman IM (1999): Effects of age on concentrations of plasma cholecystokinin, glucogon-like peptide 1 , and peptide $Y Y$ and their relation to appetite and pyloric motility. Am J Clin Nutr 69:999-1006

MacIntosh CG, Morley JE, Wishart J, Morris H, Jansen JB, Horowitz M, Chapman IM (2001): Effect of exogenous cholecystokinin (CCK)-8 on food intake and plasma CCK, leptin, and insulin concentrations in older and young adults: evidence for increased CCK activity as a cause of the anorexia of aging. Submitted for publication

Masclee AAM, Geuskens LM, Driessen WMM, Jansen JBMJ, Lamers CBHW (1988): Effect of aging on plasma cholecystokinin secretion and gallbladder emptying. Age 11:136-140

Merani S, Palmour RM, Bradwejn J, Berezowska I, Vaccarino FJ, Gutkowska J (1997): Development of a sensitive and specific assay system for cholecystokinin tetrapeptide. Peptides 18:869-875

Miyasaka K, Kitani K (1987): Aging and pancreatic exocrine function: studies in conscious male rats. Pancreas 2:423530

Miyasaka K, Kitani K (1989): Aging and pancreatic exocrine function: studies in conscious female rats. Dig Dis Sci 34:841-848

Miyasaka K, Ohta M, Masuda M, Kawanami T, Matsumoto M, Funakoshi A (1995a): Sex difference in gene expressions of cholecystokinin (CCK) and CCK receptor in young and old rats. Arch Gerontol Geriatr 21:157-165

Miyasaka K, Kanai S, Masuda M, Ohta M, Kawanami T, Matsumoto M, Funakoshi A (1995b): Gene expressions of cholecystokinin (CCK) and CCK receptors, and its satiety effect in young and old male rats. Arch Gerontol Geriatr 21:147-155

Miyasaka K, Kanai S, Ohta M, Funakoshi A (1997): Aging impairs release of central and peripheral cholecystokinin $(\mathrm{CCK})$ in male but not in female rats. J Gerontol 52A:M14-M18

Munson PJ, Rodbard D (1980): Ligand: a versatile computerized approach for characterization of ligand-binding systems. Anal Biochem 107:220-239

Ohta M, Tanaka Y, Masuda M, Miyasaka K, Funakoshi A (1995): Impaired release of cholecystokinin (CCK) from synaptosomes in old rats. Neurosci Lett 198:161-164

Peterson RA, Reiss S (1992): Anxiety Sensitivity Index Revised Test Manual. Worthington, $\mathrm{OH}$ : International Diagnostic Services

Poston GJ, Singh P, Maclellan DG, Yao CZ, Uchida T, Townsend CM, Thompson JC (1988a): Age-related 
changes in gallbladder contractility and gallbladder cholecystokinin receptor population in the guinea pig. Mech Ageing Dev 46:225-236

Poston GJ, Singh P, Draviam EJ, Upp JR, Thompson JC (1988b): Development and age-related changes in pancreatic cholecystokinin receptors and duodenal cholecystokinin in guinea pigs. Mech Ageing Dev 46:59-66

Poston GJ, Draviam EJ, Yao CZ, Townsend CM Jr, Thomp- son JC (1990): Effect of age and sensitivity to cholecystokinin on gallstone formation in the guinea pig. Gastroenterology 98:993-999

Spitzer RL, Williams JBW, Gibbons M (1995): Structured Clinical Interview for DSM-IV (SCID). New York, New York State Psychiatric Institute

Zigmond AS, Snaith RP (1983): The Hospital Anxiety and Depression Scale. Acta Psychiatr Scand 67:361-370 